\title{
MENTE, MUNDO E AUTOCONHECIMENTO: UMA APRESENTAÇÃO DO EXTERNALISMO
}

Waldomiro José da SILVA FILHO ${ }^{1}$

- RESUMO: Este texto faz considerações introdutórias sobre o argumento externalista no contexto do debate filosófico atual. Não é um resumo, um retrato fiel ou uma história do externalismo, mas uma apresentação a partir de um certo ângulo, traçando um cenário precário onde o problema da subjetividade (e os temas a ela associados, como conhecimento e racionalidade) remete à pergunta sobre qual a relação entre a mente e seus conteúdos e o mundo físico-social-lingüístico circundante.

- PALAVRAS-CHAVE: Burge; Conteúdo Mental; Externalismo; Individualismo; Putnam.

O externalismo é originalmente uma teoria em semântica filosófica e o seu problema principal diz respeito ao tema da referência e do significado. Porém essa investigação sobre o significado acabou por exigir uma perspectiva radicalmente nova sobre o conceito de mente e sobre a natureza do mental. Isso porque, no cenário da filosofia analítica contemporânea, ao externalismo está associada a afirmação de que os significados de nossas palavras e os conteúdos de alguns dos nossos estados mentais estão relacionados, ao menos em parte, com o mundo físico e/ou social.

Tyler Burge (1998a, p.21) sugere que essa imagem externalista da mente descende de uma tradição de crítica à idéia de subjetividade tal como entendida pela epistemologia moderna. De um lado, havia a tradicional con-

1 Professor Adjunto do Departamento de Filosofia e do Programa de Pós-Graduação em Filosofia da Universidade Federal da Bahia (UFBA). Artigo recebido em mar/07 e aprovado para publicação em jun/07. 
cepção cartesiana e empirista do sujeito individual centrado nas suas apercepções internas; do outro, a partir de Hegel, surgira uma progressiva ênfase na relação das instituições sociais na formação do indivíduo e dos conteúdos dos seus pensamentos. Esse segundo movimento desloca o problema do conhecimento, do pensamento, da racionalidade e da verdade para o espaço público do espírito objetivo, do mundo intersubjetivo. O externalismo, tal como podemos encontrar nas obras de filósofos contemporâneos como Hilary Putnam (1996b), Tyler Burge (1998a), Donald Davidson (1991), Saul Kripke (1972) e Ludwig Wittgenstein (2000), inspirou a formação de uma visão anti-internalista, anti-individualista, anti-subjetivista, sobre o mental que, sob muitos aspectos, transformou-se numa espécie de ortodoxia em filosofia da mente (cf. Farkas, 2003, p.187). E, além disso, reacendeu temas tradicionais, como o ceticismo a propósito do mundo exterior, de outras mentes e, sobretudo, sobre o conhecimento da própria mente.

Neste texto farei apenas algumas considerações breves e introdutórias sobre o argumento externalista no contexto do debate filosófico atual. Não farei um resumo, um retrato fiel ou uma história do externalismo, mas uma apresentação a partir de um certo ângulo. O externalismo é um tema da filosofia analítica e a principal característica deste estilo de filosofar é precisamente o intenso e animado debate entre interlocutores no campo aberto de seminários, congressos e periódicos filosóficos; por isso, não há espaço para um tratado sobre o externalismo nem há como estabelecer uma leitura que compreenda todos os ângulos do debate, pois não se trata de uma doutrina a ser apreendida, mas de um assunto, um problema de uma discussão vívida. ${ }^{2}$ Minha meta aqui se restringe a traçar um cenário precário onde se instala uma grave dificuldade filosófica: entre os filósofos externalistas, alguns estão amplamente de acordo com a crença de que os conteúdos dos nossos estados mentais intencionais (como crenças e pensamentos) são determinados, ao menos em parte, por nossa relação com o mundo externo natural, físico e social, porém eles não conseguem entrar em acordo sobre se isso é compatível ou não com a crença de que temos um conhecimento direto, autorizado, transparente e não-empírico dos nossos próprios estados mentais. Sou levado a acreditar que essa controvérsia não é apenas fruto de curiosidade filosófica, mas expressa uma dúvida, um desacordo intelectual sincero que reabre velhos e inevitáveis problemas filosóficos a propósito do modo como constru-

2 Há um intenso debate tanto sobre as conseqüências de um externalismo para a epistemologia quanto para a filosofia da linguagem e da mente. Algumas coletâneas procuram organizar o campo do debate e o estado da arte, entre elas temos: Pessin e Goldberg (1996), Ludlow e Martin (1998), Wright, Smith e Macdonald (2000), Boghossian e Peacocke (2001), Nuccetelli (2003) e Schantz (2006). 
ímos crenças sobre o mundo e sobre nós mesmos e sobre como somos capazes de pensar as garantias (ou a ausência delas) para essas crenças.

1. Para muitos filósofos, a característica de alguns dos nossos estados mentais, como crença, vontade e desejo, é que são estados mentais intencionais e têm um "conteúdo" ou um "significado" proposicional específico. Referimo-nos a esses estados mentais usando expressões frasais do tipo "João acredita que a água sacia a sede", "José deseja que seu time seja campeão". Tais estados mentais são chamados de "atitudes proposicionais" porque expressam uma "atitude" específica de um sujeito em relação a uma proposição específica (cf. Richard, 1999). Por isso temos: a crença de que [a água sacia a sede]; o pensamento de que [a democracia é o melhor regime político]; o desejo de que [o time vença], o medo de que [nosso país seja invadido por forças militares]. Assim, podemos falar do conteúdo semântico ou do significado da crença, do desejo, etc. Notemos que as frases que usei acima contêm verbos que denotam conceitos psicológicos (tais como "deseja", "imagina", "pensa").

O mental, assim considerado, é óbvio, não é compreendido num vocabulário que denote propriedades materiais ou físicas (do tipo "quebrar", "deslocar", "cair"). Isso não quer significar que o externalismo retoma o dualismo de substância mente-corpo; o que está sendo assumido é que há algo ao qual nos referimos usando um vocabulário que denota conceitos físicos e materiais (como cadeiras e estrelas) e há também algo para o qual usamos um vocabulário psicológico (como mentes, estados mentais, ações) - não está em questão aqui se há algo ontologicamente determinado que é uma coisa física ou, do outro lado, uma coisa psíquica. Mesmo assim, considera-se que, diferente de pedras, mesas e maças, estados mentais têm conteúdo representacional e são constituídos por características intencionais já que cada uma das palavras usadas para expressá-los remetem a algo além do seu próprio significado, "visam a $x$ ", "apontam para $x$ ", "intentam $x$ ". Intencionalidade aqui não é tomada como "deliberado" ou como a pretensão de realizar algo, mas como transitivo ou dirigido a alguma coisa: a crença, o pensamento, o desejo que temos são acerca de algo. É estranho dizer, nesta acepção, que alguém acredita na crença, ou deseja o desejo, ou pensa o pensamento. ${ }^{3}$

3 Essa idéia de intencionalidade está muito próxima do conceito fenomenológico de intencionalidade, tal como encontramos e. g. em F. Brentano, E. Husserl e J.-P.Sartre. Husserl escreveu: "Entendemos por intencionalidade a peculiaridade das vivências de 'ser consciência de algo'. (...) uma percepção é percepção de algo, digamos uma coisa; um julgar é o julgar de uma relação objetiva; uma valoração. De uma relação valor; um desejar, de um objeto desejado, etc." (Husserl, 1986, p.199). Sobre a intencionalidade fenomenológica, ver também Sartre, 1986. 
Há um outro aspecto em relação às atitudes proposicionais que diz respeito às suas condições de verdade: se eu falo "O Fluminense venceu a partida" a verdade ou falsidade desta frase dependerá do fato de o Fluminense ter disputado uma certa partida e de tê-la vencido. Mas o que dizer da frase "João deseja que o Fluminense vença a partida" (ou seja, "João deseja que p")? Essa frase é verdadeira se somente se João deseja algo e esse algo é "que-p". O que importa primariamente aqui é a relação entre um sujeito e uma proposição.

2. Uma pergunta que desafiou os filósofos do século XX foi: como uma frase, um pensamento, uma crença tem um conteúdo ou significado determinado? Grosso modo, podemos ter dois modos de conceber a referência ou significado: um que podemos chamar de "perspectiva descritiva" e a outra, "perspectiva não-descritiva". Para uma "perspectiva descritiva" o componente singular de um pensamento ou de qualquer outro evento mental intencional é uma descrição $F$ na qual o objeto referido é o objeto que está assentado unicamente na descrição; quando um sujeito pensa um objeto por descrição ("água", por exemplo), o conteúdo do seu pensamento parece independente do objeto particular referido pela descrição. Ou seja, meu pensamento sobre "água" será sempre o mesmo da descrição $F$, mesmo que difira no que se refere (eu posso estar diante de algo que não é água e, mesmo assim pensar que é água).

Uma perspectiva descritiva é uma forma de internalismo, pois sugere que "os conteúdos da mente podem ser descritos de um modo que não requer necessariamente uma referência ao modo como as coisas são no mundo externo - inclusive podemos pensar de um modo e o mundo ser diferente..." (cf. Schantz, 2006, p.14-6). Ora, as raízes do internalismo estão fincadas na epistemologia moderna, numa linhagem que pode ser grosseiramente traçada de Descartes até o empirismo, quando se concebeu a mente humana e todos os objetos e eventos mentais associados à idéia de interioridade. Por isso, o discurso filosófico sobre a natureza humana e sobre o lugar que a mente humana ocupa no mundo procura compreender, sobretudo, o que existe ou acontece no indivíduo, suas cognições secretas, suas estruturas cognitivas inatas, suas percepções, sentimentos e introspecções privadas e seu arsenal de idéias, significados e conceitos interiores (cf. Burge, 1998a, p.21).

A propósito desta tradição, Charles Taylor escreveu:

Em nossas linguagens de autocompreensão, a oposição "dentro-fora" representa um papel importante. Julgamos que nossos pensamentos, idéias ou emoções estão "dentro" de nós, enquanto os objetos do mundo com os quais esses estados mentais se relacionam estão "fora". Ou então pensamos em nossas capacidades ou potencialidades como "interiores", à espera do desenvolvimento que as manifestará 
ou realizará na esfera pública. (...) pensamos nas profundezas do não-dito, do indizível, dos intensos e rudimentares sentimentos, afinidades e temores que disputam conosco o controle de nossas vidas como internos. Somos criaturas com profundezas internas, com interiores parcialmente inexplorados e sombrios. (Taylor, 1997, p.149)

A mente e tudo aquilo que, na experiência humana, podemos dizer que tem um conteúdo semântico (como os nossos pensamentos, frases, intenções e crenças), segundo este ponto de vista, podem ser explicados evocando fenômenos ou processos que se passam no teatro privado, individual e isolado da mente. Chamamos de internalismo, individualismo ou subjetivismo (estes termos serão tomados aqui como significando a mesma coisa) a crença segundo a qual os conteúdos do pensamento de um sujeito são inteiramente individuados pelos estados internos ou estados intrínsecos desse sujeito (tomemos aqui tais estados internos ou intrínsecos num sentido amplo que pode incluir também estados cerebrais). Nesta tradição, "[q]uais entre nós entenderiam que nosso pensamento está em outro lugar que não dentro, 'na mente'?" (Ibidem, p.150).

Do ponto de vista de uma "perspectiva não-descritiva", um sujeito pensa num objeto não pela via da descrição, mas antes em virtude de estar em alguma relação real ou causal com o objeto. Nesta perspectiva, os pensamentos e outras atitudes proposicionais de um sujeito se conectam com seus objetos não pela descrição, mas mais diretamente em virtude da relação na qual o sujeito se encontra com aqueles objetos. O componente singular do pensamento não é equivalente a uma descrição que permanece constante em qualquer estado do mundo; antes, o conteúdo do componente singular do pensamento é individuado parcialmente pelos objetos de que trata. Imaginemos um sujeito que está diante da água e pensa ou crê que água, e que se encontra, noutro instante, numa situação contrafactual na qual está diante de algo parecido com a água, mas que não é água e ele pensa e crê que água: posto que o mundo objetivo é diferente, seus pensamentos têm, segundo uma "perspectiva não-descritiva", conteúdos diferentes. Ou seja, uma perspectiva não-descritiva sobre o significado inspira uma concepção externalista do mental e do significado.

3. O externalismo aparentemente afirma um truísmo: o significado das nossas palavras e frases e o conteúdo de nossos estados mentais intencionais estão relacionados com o mundo externo, ou seja, "os significados não estão na cabeça" (Putnam, 1996b, p.13). Grosso modo, para o externalismo, o que é pensado, o que é objeto da experiência e o que é objeto da fala depende, ao menos em parte, do mundo exterior à mente do sujeito ou, ainda, é causado pelo mundo exterior. Ou seja, os estados mentais não poderiam existir, tal como o descrevemos comumente, caso o sujeito não exista num 
mundo exterior; as atitudes proposicionais (crenças, desejos, intenções, pensamentos) não poderiam ser corretamente caracterizadas e individualizadas sem os objetos e o mundo no qual a pessoa está situada temporal e espacialmente.

O externalismo não afirma que não temos estados subjetivos ou intrínsecos; afirma apenas que os pensamentos e outras atitudes proposicionais de um sujeito não podem ser individuados no seu conteúdo inteiramente por esses estados subjetivos e intrínsecos, mas sim que podem ser individuados parcialmente pelo objetos, eventos e acontecimentos do mundo exterior à mente subjetiva.

Hilary Putnam (1996b) e Tyler Burge (1998a) demostraram que se o entorno físico ou social do sujeito se modifica em certos aspectos, necessariamente o conteúdo dos pensamentos e crenças do sujeito também se modificarão. Para ambos, fatos, objetos e acontecimentos que se dão no entorno externo (no meio ambiente físico-social) do indivíduo têm um papel na individualização dos conteúdos dos seus pensamentos:

Os anti-individualistas [ou externalistas] sustentam (...) que os conteúdos de uma atitude mental do sujeito são parcialmente individuados pelo seu [her] entorno. Eles baseam essa perspectiva argumentando que dois sujeitos idênticos em todas as suas propriedades intrínsecas, mas que estão em diferentes meio-ambientes, podem ter diferentes conteúdos de pensamento. (Brown, 2004, p.4)

Há, é claro, conseqüências filosóficas de tudo isso: se o externalismo está correto, a tese central da epistemologia subjetivista, individualista ou internalista - segundo a qual os conteúdos de um estado mental do indivíduo são inteiramente determinados pelas propriedades do indivíduo considerado isolado do mundo social e físico - deve estar errada. E, é claro, isso envolve inúmeras conseqüências.

4. Como disse acima, o externalismo se inscreve, sobretudo, no campo da filosofia da linguagem, especificamente da semântica filosófica e da investigação sobre o significado, especialmente sobre o tema da referência donde externalismo semântico. Os mais conhecidos argumentos a favor do externalismo fazem uso de experimentos mentais no qual indivíduos fisicamente idênticos se localizam em diferentes ambientes físicos ou sociais. Supõe-se então que em virtude de diferenças no meio-ambiente ocorreria que algumas crenças e pensamentos teriam um certo conteúdo num indivíduo e um conteúdo diferente em outro indivíduo intrinsecamente iguais.

Os argumentos clássicos a favor do externalismo são os argumentos das Terras Gêmeas (Twin Earth arguments) sugerido primeiramente por Hilary Putnam no artigo "The meaning of "meaning'" de 1975 (cf. Putnam, 1996b, p.3-52). Esquematicamente, segundo esse argumento, existiram 
dois planetas, a Terra e a Terra Gêmea, sendo que a Terra Gêmea é muito parecida com a Terra. De fato, ela é exatamente igual à Terra, molécula por molécula; devemos inclusive supor que um sujeito da Terra tem um sósia (Doppelgänger), uma cópia idêntica, na Terra Gêmea. Putnam imagina que há uma singela diferença entre os dois planetas: o líquido chamado "água" não é, na Terra Gêmea, $\mathrm{H}_{2} \mathrm{O}$, mas um outro líquido cuja longa e complicada fórmula química é abreviada como XYZ. Este XYZ, de qualquer maneira, é indistinguível da água em condições normais: o sabor é igual ao da água, sacia a sede como a água, enche os oceanos, lagos e rios na Terra Gêmea, etc., mas não é água. Ninguém na Terra e na Terra Gêmea pode distinguir entre "água" e XYZ - que chamarei de "água-gêmea". Então, um indivíduo que na Terra use a palavra "água" está se referindo a $\mathrm{H}_{2} \mathrm{O}$ e não XYZ (mesmo que ele não saiba, antes de 1750, que "água" é $\mathrm{H}_{2} \mathrm{O}$ ). Se por acaso ocorresse o fato extraordinário em que esse indivíduo fosse transportado para a Terra Gêmea sem ser alertado sobre essa diferença, ele usaria a mesma palavra "água" quando estivesse diante de XYZ (e o mesmo ocorreria com o seu Doppelgänger se chegasse à Terra).

Com isso, é plausível que o sujeito tenha os mesmos estados intrínsecos, inclusive os mesmos estados cerebrais, porém tenha diferentes pensamentos nos dois meio-ambientes.

... o significado é diferente porque a matéria-coisa é diferente. E eu destaquei que o falante da Terra e o seu Doppelgänger podem estar no mesmo estado cerebral neurônio por neurônio, e ainda assim poderia ser o caso de que o que o terráqueo significa pela palavra "água" não ser o que o terráqueo gêmeo significa com a mesma palavra. Foi neste ponto que escrevi: "os significados não estão na cabeça". (Putnam, 1996a, p.xvii)

Sendo assim, desde que a única diferença entre as duas situações é um entorno diferente, conclui-se que os pensamentos de um sujeito são parcialmente individuados pelo entorno. Essa variação do argumento das Terras Gêmeas é o que comumente se chama "Externalismo sobre espécies naturais" porque os conteúdos do pensamento de um sujeito são parcialmente individuados pelas espécies naturais (como substâncias químicas, objetos físicos e organismo biológicos) no seu entorno - neste caso, água.

Embora esse estilo de argumentação ainda esteja circunscrito a teses semânticas, implica problemas com relação à própria definição do mental. Consideremos que um indivíduo na Terra pronuncia com sinceridade a frase "A água sacia a sede" antes de 1750; com essa frase ele estaria expressando sua crença (seu estado mental) de que "água sacia a sede" (a crença que p), uma crença que é verdadeira se somente se " $\mathrm{H}_{2} \mathrm{O}$ sacia a sede". E se pensarmos na situação do habitante da Terra Gêmea que se encontra dian- 
te da "água-gêmea" (chamemos de "gágua"4) e que nunca encontrara ou ouvira falar em "água $=\mathrm{H}_{2} \mathrm{O}$ "? Para o argumento externalista clássico, este indivíduo na Terra Gêmea não tem a crença que "água sacia a sede", pois quando fala "A água sacia a sede" ele está expressando, na verdade, a crença que "gágua sacia a sede". Ou seja, o conteúdo de "a crença que p" tem condições de verdade diferentes nas duas situações externamente determinadas. Para ser mais direto: os dois indivíduos na Terra e na Terra Gêmea têm os mesmos estados físicos e intrínsecos, mas têm crenças diferentes.

Uma variação do argumento das Terras Gêmeas é o "Externalismo singular". Ele afirma que os conteúdos do pensamento de um sujeito são parcialmente individuados pelos objetos singulares que se encontram no seu entorno. Imaginemos que João vê uma maçã, a, e pensa que a maçã é vermelha. Nesta situação, seu pensamento se refere a uma maçã particular à qual ele observa neste exato momento - seu valor de verdade depende disto. Mas podemos pensar uma situação contrafactual na qual João, pensando que vê a maçã $a$, vê, na verdade uma outra maçã, $b$, idêntica à $a$. Aqui, João se encontra exatamente na mesma micro-estrutura, o comportamento do seu corpo é o mesmo, ele tem os mesmos estímulos na retina, porém, em virtude do fato de que ele está vendo uma maçã diferente, $b$, e não $a$, seu pensamento se refere a $b$ e não a $a$ - o valor de verdade do seu pensamento é outro (cf. Brown, 2004, p.13-5).

5. Estas formas de argumentação podem sugerir - e comumente têm sugerido - uma interpretação metafisicamente forte, ou seja, que o entendimento propriamente dito, para construir crenças verdadeiras, deve lidar com uma essência real das coisas à qual teríamos acesso através da ciência; seria, a ciência, por exemplo, que estabeleceria que água é $\mathrm{H}_{2} \mathrm{O}$ e que gágua é XYZ, determinando nossas práticas classificatórias.

No sentido de uma leitura metafisicamente mais modesta do externalismo, muitos autores, incluindo Putnam pós- "The meaning of 'meaning'", 5 atribuem um argumento externalista não-metafísico a Wittgenstein, principalmente no sentido de derivar conclusões da crítica à idéia de "linguagem privada" e do slogan "o significado é o uso" (cf. Wittgenstein, 2000, §43). Nesse externalismo modesto, para compreendermos a referência ou significado de uma palavra não devemos procurar um estado psicológico especial ou um "fato real", mas o modo como as palavras são usadas: “... o entendi-

4 Em inglês os autores usam normalmente a expressão "twin-water" e "twater".

5 Uma discussão cuidadosa do conflito entre uma leitura forte e uma leitura modesta do argumento de Putnam se encontra em Anthony Rudd, (1997). Putnam desenvolve sua crítica ao realismo metafísico em vários trabalhos, com destaque para Realism with a Human Face (1990) e Words and Life (1994). 
mento é algo que se manifesta na prática, usando apropriadamente as palavras no contexto. Logo, não se pode dizer que o entendimento existe alheio ao contexto no qual as palavras são usadas." (Rudd, 1997 p.501). Nas Notas sobre a Experiência Privada e os "Sense Data" (cf. Wittgenstein, 1968), Wittgenstein define a prioridade dos "jogos de linguagem" que nos arranca do reino fenomenológico privado para o ambiente do público. Se uma determinada expressão tem sentido, então ela pertence a uma linguagem pública:

Só se pode falar alguma coisa quando se aprendeu a falar. Se alguém, portanto, quer dizer alguma coisa, tem que ter aprendido para tanto, tem que ter aprendido a dominar uma língua; e, por certo, é evidente que pode-se querer falar, sem ter que falar. Assim como se pode querer dançar, sem dançar. (idem, 2000, §338).

Essa linguagem pública onde a vida mental se expressa é, por definição, intersubjetiva. No fundo, falar de "jogo de linguagem público" é uma redundância porque não é aceitável dizer que uma pessoa participa de um jogo de linguagem consigo mesmo. Para falar do ponto de vista subjetivo a pessoa deve adotar um conceito público disto que é o ser um "eu", "sentir dores" e "ser feliz". Wittgenstein mostra que as expressões onde a experiência interior é exteriorizada lingüisticamente pressupõem, inexoravelmente, a existência de uma linguagem pública que se joga com padrões extraídos do mundo comum.

6. Não vou me deter neste ponto. Quero somente salientar que uma outra variação do argumento das Terras Gêmeas está muito próximo desse espírito witgensteiniano, a saber, o "Externalismo social". O "Externalismo social" afirma que os pensamentos de um sujeito são individuados parcialmente pela prática da sua comunidade lingüística. O externalismo social está baseado num experimento mental que estipula um mundo possível no qual todos os elementos e acontecimentos físicos do mundo atual são idênticos ao mundo contrafactual. Simultaneamente, imaginam-se algumas variações nas convenções lingüísticas e nas normas de seu emprego. A conclusão é que os estados mentais atribuídos ao agente serão diferentes, mesmo se os acontecimentos e eventos forem os mesmos.

Suponhamos que João tenha sofrido de artrite durante vários anos e tenha freqüentado o seu médico durante esse período e nessas situações ele e o médico usaram o termo "artrite" para se referir à sua enfermidade (como "Eu tenho artrite no meu tornozelo", "A artrite é dolorosa e debilitante", "A artrite é comum na idade mais avançada"). Num certo dia João afirma "Eu tenho medo que minha artrite atinja minha coxa". Esta atitude expressa que João não compreendeu corretamente a definição de "artrite", que, na 
verdade, aplica-se a problemas das articulações. Pensemos, então, numa situação contrafactual na qual João se encontra numa comunidade lingüística diferente e na qual "artrite" tem uma definição diferente (uma extensão semântica diferente). Ao passo que na situação atual "artrite" é definida para se aplicar a doenças das articulações, na situação contrafactual, sua definição se aplica tanto a doenças das articulações quanto a doenças musculares; na situação contrafactual, "artrite" expressa um conceito diferente que Burge chama de "tartrite" (em inglês: tharthritis). Considerando que a diferença entre a situação atual e a situação contrafactual é o modo como "artrite" é definida pela comunidade lingüística, Burge conclui que os pensamentos do sujeito não são individuados completamente pelos seus estados intrínsecos, mas são individuados parcialmente pela prática lingüística da comunidade.

... o que uma pessoa crê que significam as suas palavras, como as toma, determina completamente que atitudes pode expressar ao usá-las: o conteúdo de seus estados e eventos mentais estão estritamente limitados a noções que ele entende... (Burge, 1998a, p.59)

As diferenças sociais, segundo Burge, entre a situação real e a situação contrafactual afetam necessariamente o conteúdo dos pensamentos e atitudes do sujeito. Donde a afirmação de que "Nenhum fenômeno mental intencional do homem é insular. Todo homem é uma parte do continente social..." [grifos meus] (Ibidem, p.39-40). Quando João pronuncia sinceramente a frase "Eu tenho artrite na minha coxa" ele está expressando a crença verdadeira para sua comunidade lingüística de que "tem tartrite na coxa"; se ele se encontra na situação real, esta frase é falsa, mas se se encontra na situação contrafactual, é verdadeira. Embora os estados intrínsecos dos indivíduos que vivem nas comunidades lingüísticas diferentes sejam os mesmos, suas crenças são diferentes. Posto que as duas situações diferem exclusivamente no uso lingüístico, isso deve nos levar a concluir que o conteúdo mental depende em parte da prática lingüística comunitária.

Para Tyler Burge, o externalismo refuta as teorias individualistas dos estados mentais intencionais - donde o seu externalismo ser chamado de anti-individualismo. As teorias individualistas defendem que para uma pessoa ter um estado mental intencional (ter uma crença ou pensamento) é suficiente e necessário apenas fatos intrínsecos sem referência ao entorno. Este é o caso do que se conhece como "teorias da identidade mentecérebro" que afirmam que cada ocorrência de um estado mental particular é idêntico a uma ocorrência de um estado cerebral particular. Os argumentos externalistas se empenham em demonstrar, como podemos inferir dos experimentos de Putnam e Burge, que os estados cerebrais de um indiví- 
duo podem permanecer os mesmos, mesmo se o entorno físico e lingüístico for diferente.

7. Passando em revista rapidamente os traços gerais dos argumentos externalistas, encontramo-nos finalmente diante de um problema: a crítica à imagem da mente como um teatro no qual o eu contempla um espetáculo e à idéia de um conhecimento-de-si como um conhecimento introspectivo, infalível e incorrigível, levaria o externalismo a inverter o ceticismo cartesiano? Então nossas crenças sobre o mundo-entorno passariam a gozar de uma autoridade inerente porque a maioria massiva delas seriam verdadeiras, mas poderíamos facilmente estar equivocados sobre o que pensamos, ou ainda, não conhecemos o conteúdo de nossas mentes?

Se para o externalista o que um sujeito pensa depende do seu entorno e, em particular, de fatos como o da composição química das substâncias e da prática lingüística de uma comunidade, então isso deve sugerir que o externalismo implica num resultado contra-intuitivo segundo o qual o sujeito pode conhecer o conteúdo do seu próprio pensamento apenas investigando a composição química das substâncias ou a prática lingüística da comunidade. Também podemos ser induzidos a pensar que aquilo que tradicionalmente é chamado de "conhecimento introspectivo", "conhecimento dos próprios estados mentais", a "autoridade da primeira pessoa" simplesmente não é o caso - ao falarmos de nós mesmos estaríamos aplicando as palavras "saber" e "conhecer" indevidamente.

Há uma outra opção: se os filósofos estiverem dispostos a aceitar a possibilidade de conhecermos as nossas próprias mentes e de termos conhecimento a priori eles também podem concluir que o externalismo é falso.

8. Vejamos um exemplo de argumento no estilo das Terras Gêmeas que defende a incompatibilidade entre externalismo e autoconhecimento. ${ }^{6}$ podemos pensar numa situação na qual um sujeito é transportado entre dois diferentes ambientes físicos ou lingüísticos, por exemplo, entre as nossas já conhecidas Terra e Terra Gêmea, mas esse sujeito não tem como discriminar entre os dois lugares (conhecido como slow switching case). Se aceitamos que a aquisição de conceitos pelo sujeito depende de fatores que se dão no tempo e lugar onde ele se encontra (na Terra ou na Terra Gêmea), então quando ele tem o pensamento que é expresso pela frase "Há água aqui", ele tem um pensamento sobre "água" se somente se está na Terra ou sobre "água-gêmea" se somente se está na Terra Gêmea. Porém, se o sujeito

6 Entre os textos mais influentes que afirmam que há uma incompatibilidade entre externalismo e autoconhecimento encontramos Boghossian (1989, 2000) e McKinsey (1998, 2000). 
não tem como distinguir se está na Terra ou na Terra Gêmea, ele também não pode conhecer, recorrendo apenas à introspecção se está tendo um pensamento sobre "água" ou sobre "água-gêmea", ou seja, não pode conhecer através do auto-exame do conteúdo do seu pensamento, sem recorrer a um exame do entorno, qual o conteúdo do seu próprio pensamento.

Não precisamos ir muito longe para conceber isso. Alguns filósofos afirmam que isso pode ser concebido na mudança de comunidades lingüísticas (cf. Ludlow, 1998, p.225-30), quando, por exemplo, alguém se encontra numa certa situação onde falantes do mesmo idioma usam a mesma palavra com significados diferentes, mas que nosso falante não sabe dessa mudança de significado.

O argumento incompatibilista concebe que um indivíduo não poderia distinguir entre a situação atual na qual ele pensa "a água sacia a sede" e a situação contrafactual na qual ele, de fato, não tem tal pensamento, mas o pensamento "a água-gêmea sacia a sede". Aqui não há a transparência, a autoridade e o acesso privilegiado que caracterizariam o autoconhecimento, já que ele não sabe distinguir o pensamento que ele mesmo tem sem que outra pessoa o informasse que não se encontra na Terra, mas na Terra Gêmea e lhe esclarecesse a diferença entre pensar-que-água e pensar-queágua-gêmea. Como alguém poderia conhecer o que pensa se não consegue distinguir a situação e o entorno no qual tem o pensamento atual?

9. Uma argumentação compatibilista, porém, sustenta que embora certas condições externas de fato devam comparecer para que os pensamentos sejam o que são e tenham um conteúdo específico, conhecer que o pensamento ocorre (que temos um pensamento com um conteúdo específico) não depende de conhecer todas as condições que possibilitam nossos pensamentos e juízos, inclusive as condições externas, de modo absoluto. ${ }^{7}$ Em todos os casos que envolvem conhecimento, não somos oniscientes; não seria de se esperar que o fôssemos em questões de autoconhecimento.

O ponto central de um argumento compatibilista implica numa distinÇão no objeto do pensamento: de um lado, o conteúdo de um pensamento de primeira-ordem, de fato, depende do entorno e tem como objeto algo que se refere à cadeia causal entre mente e mundo; um exemplo disso é o pensamento "a água sacia a sede". Do outro lado, o status epistêmico específico de um juízo ou pensamento de segunda-ordem sobre o conteúdo do pensamento de primeira-ordem não tem os mesmos critérios de verdade em

7 Entre os textos que apresentam um argumento que defende que há compatibilidade entre externalismo e autoconhecimento encontramos: Bilgrami (1996), McLaughlin e Tye (1998), Faley (2000). 
relação ao entorno; um exemplo é "penso que a água sacia a sede". Esses juízos e pensamentos seriam caracteristicamente auto-verificáveis já que ter tais juízos e pensamentos faz com que seja verdadeiro dizer que se os tem e, mais, dizer que sabe que se os tem. Se penso "Acredito (ou julgo ou duvido) que a água sacia a sede", seria uma condição necessária que eu me encontre em tal estado mental no qual acredito (ou julgo ou duvido) que a água sacia a sede.

Estabelecido isso, parece que não faz sentido uma controvérsia em relação às condições que determinam o conteúdo do pensamento de primeira-ordem: para pensar que algo é água é necessário estar em alguma relação causal com a água (ou ao menos em alguma relação causal com uma substância que nos habilite a teorizar sobre água). Nos casos normais, vêse e toca-se na água. Essas relações ilustram o tipo de condição que torna possível pensar algo sobre água e envolve métodos e procedimentos empíricos. Conhecer o que se está pensando quando se tem pensamentos sobre entidades físicas, pressupõe alguma das condições semelhantes às que determinam o conteúdo do pensamento empírico que se conhece quando se pensa. Este é o resultado do caráter de segunda-ordem dos pensamentos. A possibilidade cognitiva de um juízo sobre pensar que a água é um líquido deve estar fundada na habilidade de pensar que a água é um líquido.

O fato de que não podemos recorrer a investigações empíricas para discriminar nossos pensamentos de outros pensamentos que poderíamos ter se estivéssemos em outro entorno, não mina nossa habilidade de conhecer o que são nossos pensamentos. Nós individualizamos nossos pensamentos ou os discriminamos de outros pensamentos exatamente pensando aquele pensamento e não outro, auto-atributivamente (cf. Burge, 1998b, p.119)

Do mesmo modo, os casos paradigmáticos de autoconhecimento são essencialmente pessoais; eles dependem de que o juízo realiza-se simultaneamente do próprio ponto de vista da primeira pessoa e sobre o ponto de vista da primeira pessoa. Quando eu julgo: "Eu estou pensando que escrever requer concentração", o tempo do juízo e o tempo do pensamento que está sendo julgado são os mesmos; e a identidade do pronome da primeira pessoa assinala e identifica o ponto de vista entre o juízo e o pensamento sobre algo.

10. Tenho minha própria opinião sobre esse assunto e a desenvolvi alhures (cf. Silva Filho, 2006, 2007a). É o que chamo de "externalismo deflacionado" (idem, 2005) e "externalismo sem dogmas" (idem, 2007b). Para mim, o problema mais grave com o externalismo é o fato de que ele normalmente depende de uma imagem muito dramática das precariedades e incapacidades reivindicadas para o homem. A idéia de "estar enganado", por 
exemplo, no debate externalista, extrapola em muito o sentido comum de erro e engano. O "erro", o "engano", a "vulnerabilidade" de que tanto se fala e que tanto estrago tem causado depende não apenas que percebamos que erramos aqui e acolá ou de que alguém nos diga isso, mas de algo que tenho chamado de perspectiva do narrador onisciente ${ }^{8}$ que arquiteta armadilhas lógicas e, ao nos perguntar se o conhecimento de si é o caso, retira-nos do contexto usual do pronome "eu", da "dúvida" e das atitudes comuns do tipo "eu sei que", "eu acredito que". Pensamos a possibilidade e impossibilidade de nossas crenças terem os conteúdos que têm, de nossas palavras terem o significado que têm, de pensarmos nossos pensamentos e pensarmos sobre nós mesmos de um ponto de vista de outra pessoa que conhece mais sobre nós e sobre nosso entorno do que nós mesmos.

Com Davidson, sugiro que devemos pensar na situação corriqueira da conversa, da interlocução, da disputa. O conhecimento e a verdade não são acontecimentos que se dão na solidão do indivíduo tomado isoladamente em relação ao mundo e à sociedade. Nossas atitudes proposicionais são objetivas não porque foram formadas à luz de alguma evidência, mas porque são verdadeiras ou falsas na conversa com os outros. Por isso, a objetividade é conseqüência daquilo que ele chama de triangulação (cf. Davidson, 2001b): o conteúdo do pensamento de uma pessoa depende das suas relações com outras pessoas e com o mundo, de modo que para que se dê tal triangulação se requer dois seres (supostamente racionais) que interagem com um objeto e que se inscrevem, pela interpretação radical, num diálogo. Porque ambos partilham o conceito de verdade lhes é permitido dar um sentido à suposição de que cada um deles tem uma crença verdadeira sobre um mundo objetivo. O intérprete, para compreender a fala do outro, parte da suposição que a maioria das frases que um falante tem por verdadeiras - especialmente aquelas que sustenta com mais obstinação, as mais centrais no sistema de suas crenças - são verdadeiras, ao menos na opinião do intérprete. O único método à disposição do intérprete põe automaticamente as crenças do falante de acordo com seus próprios critérios lógicos. A idéia de um autoconhecimento e de uma autoridade da primeira pessoa é, deste modo, algo simples: apenas é de se supor que conheço o que signifi-

8 Quando falo de um "narrador onisciente" não estou falando de um novo experimento mental ou de um novo personagem que vem compor os experimentos mentais comuns aos argumentos externalistas. Os experimentos mentais têm invariavelmente a mesma estrutura narrativa: demonstram que os nossos estados mentais estão relacionados com entorno, mas que muitas vezes desconhecemos o verdadeiro conteúdo deste estado mental porque desconhecemos a coisa-matéria que compõe o mundo onde habitamos atualmente ou desconhecemos a referência das palavras que usamos. Ou não podemos discriminar as condições em que os nossos pensamentos e palavras têm o conteúdo que supomos ter. 
co, enquanto o mesmo não se passa com outra pessoa em relação a mim, pois elas, de partida, não conhecem do mesmo modo que eu o que eu intento e creio ao expressar minhas declarações... por isso elas devem interpretar radicalmente o que eu falo (cf. idem, 2001a). Quando interpretamos as ações e falas dos outros presumimos que eles têm a mesma autoridade sobre suas crenças e desejos.

Aceitar uma autoridade da primeira pessoa parece ser uma condição para a atividade de interpretação. Para Davidson, a existência da autoridade da primeira pessoa não é um fato empírico, mas antes um critério, entre outros, do que é um estado mental. E, dado que as bases para se atribuir um estado mental aos outros são tão diferentes das bases para se atribuir um estado mental a nós mesmos, por que deveríamos pensar que eles são o mesmo tipo de estado? Davidson acha que a resposta para este enigma é simples: devemos interpretar os pensamentos dos outros na base da evidência; interpretar a nós mesmos (salvo em casos especiais) não faz sentido.

Além disso, a conversa comum não é possível sem que concebamos que quando um falante diz, em referência a si mesmo, que tem uma crença, desejo ou intenção, existe uma presunção de que ele não se engana quanto a isso. Fora das filosofias da consciência modernas não há sentido perguntar se conhecemos o mundo exterior, outras mentes ou a própria mente. Fora desse quadro de referências, podemos pensar nosso pensamento (e outros estados mentais) num "envolvimento ordinário, cotidiano com o mundo" (Malpas, 2005, p.51). Devemos abandonar a idéia que o mundo é qualquer coisa além do que é dado no e através do nosso envolvimento contínuo e cotidiano com as coisas ou que as nossas crenças podem estar baseadas em alguma outra coisa que não seja esse envolvimento cotidiano.

11. Também Burge, no meu entendimento, favorece um externalismo sem dogmas. Se não me engano, a argumentação de Burge a favor de nossa "pretensão legítima" ao autoconhecimento e à autoridade da primeira pessoa trata de algo que é constitutivo da nossa atitude mental cotidiana (Burge, 1998c, p.241). No dia-a-dia formulamos juízos cujos objetos são nossos próprios estados, crenças, pensamentos, e nisso está implicada tal capacidade de refletir e reivindicar razões. Realmente, não é incomum concebermos e empregarmos um raciocínio crítico ou recorrer a razões e raciocínio. Não é tão raro assim avaliarmos, ponderarmos, criticarmos, julgarmos nossos pensamentos, atitudes e ações, principalmente quando queremos dar uma prova, planejar algo, conversar com outras pessoas, justificar, explicar, enfim, quando queremos oferecer razões - no sentido trivial, não-filosófico, de "ter razões". Para Burge, isso claramente requer uma habilidade de segunda-ordem para pensar sobre os conteúdos dos nossos pensamentos ou 
proposições de primeira-ordem (cf. idem, 1998b, p.246); numa palavra, isso envolve autoconhecimento.

Burge, ademais, considera necessário para a prática do raciocínio crítico não apenas o autoconhecimento básico (basic self-knowledge) no presente do indicativo, mas também a memória preservativa, pois ela nos provê de um conhecimento dos nossos estados e pensamentos passados (cf. idem, 1995, 1998b, 1998c, 2000). A tal "pretensão legítima" permanece constante mesmo diante da possibilidade de mudanças no meio-ambiente ou de conteúdos conceituais que ignoramos como pensadores e falantes contingentes.

12. Isto é tudo que devemos esperar do externalismo: considerar que a autoridade da primeira pessoa, a perspectiva da terceira pessoa e o caráter social da linguagem, no contexto intersubjetivo da interpretação e da conversa comum, devem se combinar e não se excluir.

SILVA Filho, Waldomiro José da. Mind, world and self-knowledge: an introduction to externalism. Trans/Form/Ação, (São Paulo), v.30(1), 2007, p.151-168.

- ABSTRACT: This text gives some introductory considerations on the argument of externalism in context of the current philosophical debate. It is not a summary, a faithful image or the history of externalism, but a presentation starting from a certain angle, outlining a precarious scenery where the problem of subjectivity (and the themes associated therewith, such as knowledge and rationality) leads to the question of what the relationship is between on the one hand the mind and its content and on the other hand the physical-social-linguistic world surrounding it.

- KEYWORDS: Burge; Mental Content; Externalism; Individualism; Putnam.

\section{Referências bibliográficas}

BILGRAMI, A. Can externalism be reconciled with self-knowledge. In: PESSIN, A. e GOLDBERG, S. (Eds.). The Twin Earth Chronicles: Twenty Years of Reflection on Hilary Putnam's "The meaning of 'meaning'". New York, London: M. E. Sharpe, 1996, p.362-93.

BOGHOSSIAN, p.A. Content and self-knowledge. In: Philosophical Topics, n.17, 1989, p.5-26.

What the externalism can know a priori. In: WRIGHT, C., SMITH, B. C. e MACDONALD, C. (Eds.). Knowing Our Own Minds. Oxford: Clarendon, 2000, p.271-83. 
BOGHOSSIAN, p.A. e PEACOCKE, Ch. (Eds.) New Essays on the A Priori. Oxford: Oxford University Press, 2001.

BROWN, J. Anti-individualism and Knowledge. Cambridge, London: MIT Press, 2004.

BURGE, T. Individualism and the Mental. In: LUDLOW, p.e MARTIN, N. (Eds.). EXternalism and Self-Knowledge. Stanford : CSLI Publications, 1998a, p.21-83.

Individualism and Self-knowledge. In: LUDLOW, p.e MARTIN, N. (Eds.), Externalism and Self-Knowledge. Stanford: CSLI Publications, 1998b, p.11127.

Our Entitlement to Self-knowledge. In: LUDLOW, p.e MARTIN, N. (Eds.), Externalism and Self-Knowledge. Stanford: CSLI Publications, 1998c, p.23963.

Reason and the First Person. In: WRIGHT, CRISPIN, SMITH, BARRY C. e MACDONALD, C. (Ed.). Knowing Our Own Minds. Oxford: Clarendon, 2000, p.243-69.

DAVIDSON, D. Epistemology Externalized. In: Dialectica, v.45, n.2-3 (1991), p.191202.

First Person Authority. In: Subjective, Intersubjective, Objective. Oxford: Clarendon Press, 2001a, p.3-14.

Rational Animals. In: Subjective, Intersubjective, Objective. Oxford: Clarendon Press, 2001a, p.95-105.

FALEY, K. The Compatibility of Anti-individualism and Privileged Access. In: Analysis, n.60.1, 2000, p.137-42.

FARKAS, K. What is Externalism? In: Philosophical Studies, n.112, 2003.

HUSSERL, E. Ideas Relativas a una Fenomenología Pura y una Filosofía Fenomenológica, trad. José Gaos. México: Fondo de Cultura Económica, 1986.

KRIPKE, S. Naming and Necessity. Oxford: Basil Blackwell, 1972.

LUDLOW, p. Externalism, Self-knowledge, and the Prevalence of Slow Switching. In: LUDLOW, p.e MARTIN, N. (Eds.). Externalism and Self-Knowledge. Stanford: CSLI Publications, 1998, p.225-29.

LUDLOW, p. e MARTIN, N. (Eds.). Externalism and Self-Knowledge. Stanford : CSLI Publications, 1998.

MALPAS, J. Não renunciar ao mundo, trad. C. Bacelar. In: SMITH. p.J. e SILVA FILHO, W. J. (Orgs.). Significado, Interpretação, verdade: Davidson e a Filosofia. São Paulo : Loyola, p.51-65.

McKINSEY, Michael. "Anti-individualism and Privileged Access". In: p.Ludlow e N. Martin (Eds.). Externalism and Self-Knowledge. Stanford : CSLI Publications, 1998.

"Form of externalism and privileged access". In: Philosophical Perspectives, n.16, 2000, p.199-224.

McLAUGHLIN, Brian p.e TYE, Michael. "Is Content-externalism compatible with Privileged Access?". In: The Philosophical Review, n.107, 1998, p.349-380. 
NUCCETELLI, Susana (Ed.). New Essays on Semantic Externalism and Self-knowledge. Cambridge, London : MIT Press, 2003.

PESSIN, A. e GOLDBERG, S. (Eds.) The Twin Earth Chronicles: Twenty Years of Reflection on Hilary Putnam's "The meaning of 'meaning'". New York, London: M. E. Sharpe, 1996.

PUTNAM, H. Introduction. In: Andrew Pessin e Sanford Goldberg (Ed.). The Twin Earth Chronicles: Twenty Years of Reflection on Hilary Putnam's "The meaning of 'meaning'". New York, London: M. E. Sharpe, 1996a.

"The Meaning of 'Meaning'". In: PESSIN, A. e GOLDBERG, S. (Eds.). The Twin Earth Chronicles: Twenty Years of Reflection on Hilary Putnam's "The meaning of 'meaning'". New York, London: M. E. Sharpe, 1996b, p.3-52.

. Realism with a Human Face. Cambridge, London: Harvard University Press, 1990.

Words and Life. Cambridge, London: Harvard University Press, 1994.

RICHARD, M. Propositional Attitudes. In: HALE, B. e WRIGHT, C. (Eds.), A Companion to the Philosophy of Language. Oxford, Cambridge: Basil Blackwell, 1999, p.197-226.

RUDD, A. "Two Types of Externalism". In: Philosophical Quartely, v.47, n.189, October, 1997, p.501-7.

SARTRE, J.-p.L'Imaginaire. Paris : Gallimard, 1986.

SCHANTZ, Richard (Ed.) The Externalist Challenge. Berlin, New York : Walter de Gruyter, 2006.

SILVA FILHO, Waldomiro J. "Externalismo, Autoconhecimento e Ceticismo". In: SILVA FILHO, Waldomiro J. e SMITH, Plínio (Orgs). Ensaios sobre Ceticismo. São Paulo: Alameda, 2006.

O Autoconhecimento, o Narrador Onisciente a Vida Comum. In: Philósophos, 2007a, no prelo.

Externalismo sem Dogmas. In: O Que nos Faz Pensar, 2007, no prelo.

TAYLOR, Charles. As Fontes do Self: A construção da identidade moderna, trad. Adail U. Sobral e Dinah de A. Azevedo. São Paulo: Loyola, 1997.

WITTGENSTEIN, L. Notes for Lectures on "Private Experience" and "Sense Data". In: Philosophical Review, v. 77, n.3, 1968, p.275-320.

Philosophical Investigations. Oxford, Cambridge: Basil Blackwell, 2000.

WRIGHT, C., SMITH, B. C. e MACDONALD, C. (Ed.). Knowing Our Own Minds. Oxford: Clarendon, 2000. 